Provided for non-commercial research and education use. Not for reproduction, distribution or commercial use.

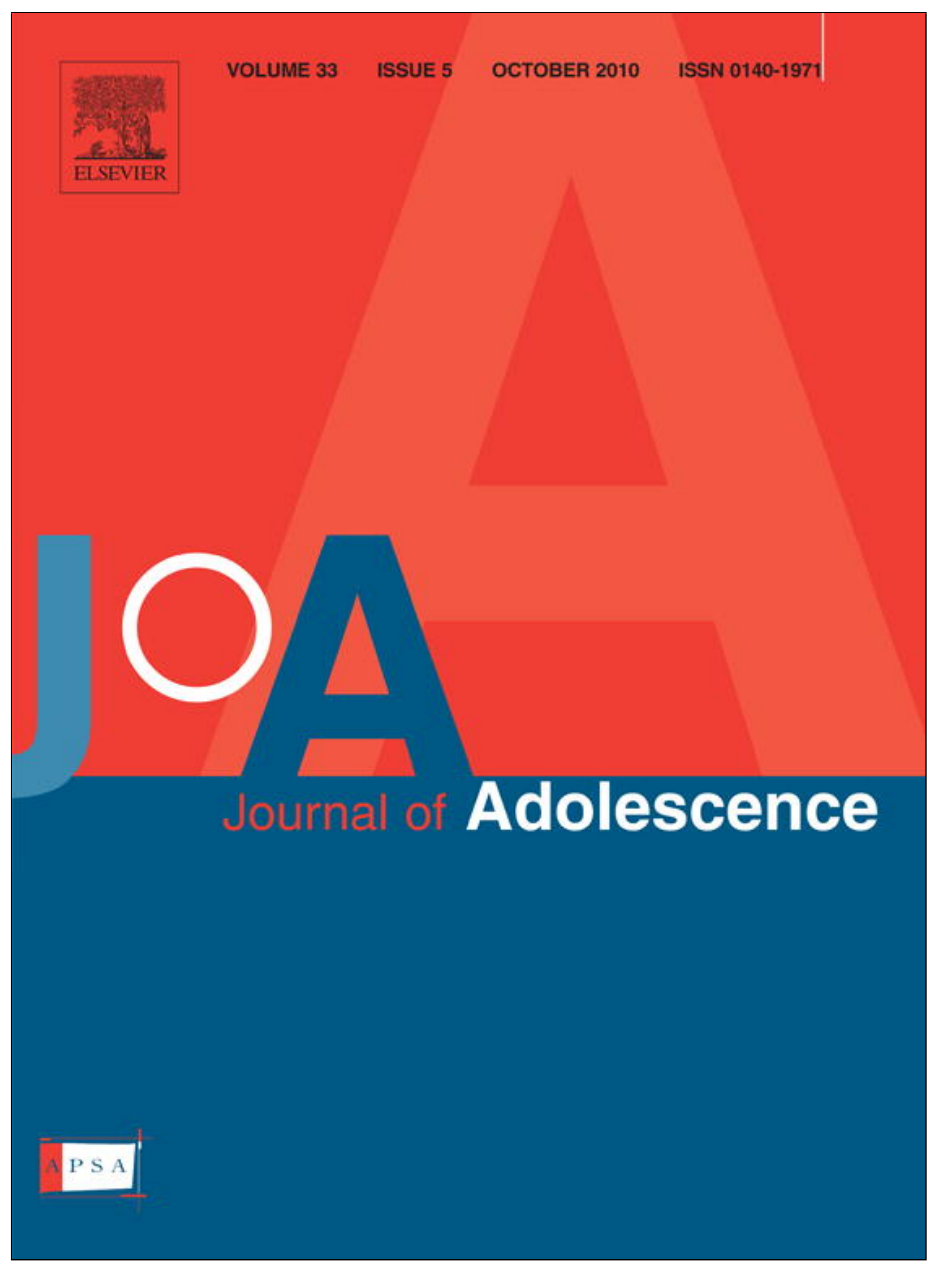

This article appeared in a journal published by Elsevier. The attached copy is furnished to the author for internal non-commercial research and education use, including for instruction at the authors institution and sharing with colleagues.

Other uses, including reproduction and distribution, or selling or licensing copies, or posting to personal, institutional or third party websites are prohibited.

In most cases authors are permitted to post their version of the article (e.g. in Word or Tex form) to their personal website or institutional repository. Authors requiring further information regarding Elsevier's archiving and manuscript policies are encouraged to visit:

http://www.elsevier.com/copyright 


\title{
Culture-general and -specific associations of attachment avoidance and anxiety with perceived parental warmth and psychological control among Turk and Belgian adolescents ${ }^{\text {is }}$
}

\author{
Derya Güngör ${ }^{\mathrm{a}, *}$, Marc H. Bornstein ${ }^{\mathrm{b}}$ \\ ${ }^{a}$ K.U. Leuven, Center for Social and Cultural Psychology, Tiensestraat 102- bus 03727, B-3000 Leuven, Belgium \\ ${ }^{\mathrm{b}}$ Eunice Kennedy Shriver National Institute of Child Health and Human Development, National Institutes of Health, Department of Health and \\ Human Services, USA
}

\section{Keywords:}

Adolescents

Peer attachment

Psychological control

Parental warmth

Attachment styles

Culture

\begin{abstract}
A B S T R A C T
Both the adolescent peer attachment and perceived parenting style literatures emphasize the role of the quality of the parent-child relationship in children's healthy adjustment beyond the family, but few studies have investigated links between adolescents' peer attachment and perceptions of parenting. We investigate relations of adolescents' perceptions of warmth and psychological control from parents with avoidance and anxiety in attachment to close friends in two contrasting cultures. Altogether, 262 Turk and 263 Belgian youth between 14 and 18 years of age participated. Cross-culturally, attachment avoidance was negatively related to maternal warmth, and attachment anxiety positively related to maternal and paternal control and negatively to paternal warmth. Beyond these general relations, attachment avoidance was associated with paternal psychological control in Belgians but not in Turks. The study provides cross-cultural evidence for specific relations between peer attachment and perceived parenting and suggests a culturespecific pathway for the development of attachment avoidance.

(c) 2009 The Association for Professionals in Services for Adolescents. Published by Elsevier
\end{abstract} Ltd. All rights reserved.

Adolescence is a time during which children explore intimate, supportive relationships and develop mutual attachments outside the family (Steinberg \& Silk, 2002). Throughout adolescence, peers (as close friends or as romantic partners) become increasingly important for attachment functions, for example, as close and secure confidants to turn to in times of stress (Allen \& Land, 1999). As a gradual shift of primary attachment from parents to peers occurs (Fraley \& Davis, 1997), parents remain central in lives of adolescents. From attachment perspective, representations of interactions with parents form the basis of individual differences in attachment security in childhood and continue to do so in later ages in relationships with others (e.g., Fraley \& Shaver, 2000; Mikulincer, Shaver, \& Pereg, 2003). In fact, the quality of peer attachment is believed to depend heavily on the quality of relationships with parents (e.g., Dekovic \& Meeus, 1997).

From the perspective of research linking parenting styles to child outcomes, however, adolescents' experiences of the ways their parent's parent have been shown to be important for youth (e.g., Barber, Stolz, \& Olsen, 2005; Khaleque \& Rohner, 2002). On this basis, one might expect individual differences in adolescents' attachment to peers to be closely related to experiences with different parenting styles. That said, research relating perceived parenting to peer attachment is lacking, which is

\footnotetext{
is Preparation of this article was supported by the EU Marie Curie International Fellowship awarded to Derya Güngör and by the Intramural Research Program of the NIH, NICHD. Special thanks to Dr. Nebi Sümer for his earlier contribution to this study.

* Corresponding author.

E-mail address: Derya.Gungor@psy.kuleuven.be (D. Güngör).
} 
especially regrettable in light of more and more refined conceptualizations of each of these constructs through recent decades. Our goal was to begin to fill this gap by evaluating specific features of attachment to peers and perceived parenting from a parsimonious framework and in a culturally comparative way. Juxtaposing the central dimensions of each construct may open the way to more advanced and revealing explanations of parenting-related factors associated with optimal functioning in key relationships during adolescence. The cross-cultural contrast permits insight into the degree to which findings about hypothesized links between parenting and attachment can be generalized.

In research on attachment in adolescence, mainstream focus has fallen on mother-adolescent relationships, hence "there is a glaring absence of literature about teen-father relationships" (Day \& Acock, 2004, p. 277). Although the experience of love and concern from fathers is as important in the psychosocial development and well-being of adolescents as is that from mothers (see Rohner \& Veneziano, 2001, for a review), this relationship has been much less studied, and relatively little work has included assessments of mothers and fathers simultaneously (e.g., Soenens et al., 2005). Still unexplored too are specific adolescent outcomes associated with fathering dimensions in non-Western societies where parental roles and father-child relationships differ from those in the Western context (Bornstein \& Lansford, 2009). For example, fathers in non-Western cultures, such as in Chinese and Turkish societies are seen as authority figures whose restrictive control is goal-oriented and more expected (Kağıtçıbaşı, 1970; Yang et al., 2003). Therefore, we collected data on adolescents' perceptions of mothering and fathering in both non-Western (Turkey) and Western (Belgium) societies.

\section{From attachment to parenting dimensions}

Researchers agree that attachment styles can best be conceptualized as falling along two distinct dimensions, an avoidance dimension that reflects interpersonal distance and an anxiety dimension that represents the degree of fear of rejection and dependence on others for approval and self-worth (Bartholomew \& Horowitz, 1991; Brennan, Clark, \& Shaver, 1998; Mikulincer et al., 2003). Research on adolescent attachment in relationships with close friends and romantic partners has shown that avoidance is positively linked to outcomes such as reluctance to seek proximity and intimacy with others, compulsive self-reliance, distrust of others, indifference to others' problems, perceiving others as not supportive, and low self-disclosure (e.g., Brennan et al., 1998; Kobak \& Sceery, 1988; Sümer \& Güngör, 1999a). By contrast, anxiety is associated with dependence on others' confirmation and acceptance for self-worth, affect-regulation problems such as extreme emotional reactions, spread of negative emotions and memories, low satisfaction with the support and concern of others, jealousy and intervention, and excessive proximity seeking (e.g., Bartholomew \& Horowitz, 1991; Brennan et al., 1998; Mikulincer \& Orbach, 1995). Adolescents' attachment anxiety is also closely linked to internalizing problems, such as self-reported depression (Allen, Moore, Kuperminc, \& Bell, 1998). Accordingly, we assessed attachment avoidance and anxiety in relationships with close friends among two culturally contrasting samples of adolescents, Belgians and Turks, and defined secure attachment in terms of relatively low level avoidance and anxiety (Brennan et al., 1998).

Research on adolescent attachment and adult memories of early experiences has revealed that adolescents high on avoidance report their parents as rejecting, cold, unengaged, and distant; adolescents high on anxiety describe their parents as overprotective, intrusive, and overcontrolling (Hazan \& Shaver, 1987; Kobak \& Sceery, 1988; Levy, Blatt, \& Shaver, 1998). Hence, the main theme in parental representations of avoidant and anxious individuals seems to be differential levels of behaviors which are akin to two dimensions of perceived parenting styles-parental warmth and parental psychological control, respectively. Warmth includes acceptance, engagement, and responsiveness; parents high on this dimension show affectionate intimacy, acceptance, involvement, and love in the eye of their children (Rohner, 1986). Psychological control is related to dominating the child's psychological world through intrusion, love withdrawal, and expecting absolute compliance (Barber, 1996). As we detail below, it is evident in cross-cultural research that the experience of warmth has universal significance for healthy adjustment (Rohner, 1986), but the meaning, and thus consequences, of psychological control vary depending on whether it is perceived in the context of warmth or not. That being said, too little attention has been paid to psychological control in the context of warmth (Doyle \& Markiewicz, 2005). Therefore, it is important to determine culturegeneral and -specific patterns of relations between perceived psychological control and adolescent outcomes to develop more a precise understanding of the meaning of psychological control.

\section{From parenting to attachment dimensions}

Studies of perceived warmth and psychological control have yielded remarkably consistent findings in terms of correlates. Cross-culturally, warmth has been shown to be positively associated with healthy adolescent adjustment across cultures (see Khaleque \& Rohner, 2002, for a meta-analysis) and particularly with social initiative and positive attitudes towards interpersonal interaction (e.g., Barber et al., 2005), which is reminiscent of the defining characteristic of individuals who are low on attachment avoidance. Barber et al. accounted for this link with reference to attachment theory in which supportive parenting promotes the development of positive expectations about self and others, which in turn facilitates positive interactions with the social environment.

By contrast, perception of high psychological control seems to be distinctively linked to attachment anxiety-related problems, mainly to internalization such as depression, anxious symptomology, somatization, and low self-confidence (Barber, 1996; Barber et al., 2005; Conger, Conger, \& Scaramella, 1997). Moreover, the link between psychological control and adolescent internalization is robust across cultures (see Sorkhabi, 2005, for a review). For example, psychological control, as 
measured by combined mother- and adolescent-reports, was found to be associated with low self-esteem, maladaptive perfectionism, and the severity of depression in Belgian adolescents, and this relation remained significant even after parental warmth was controlled for (Soenens, Luyckx, Vansteenkiste, Duriez, \& Goossens, 2008; Soenens, Vansteenkiste, Luyten, Duriez, \& Goossens, 2005). Güngör (2008) found that psychological control was linked with low self-esteem in both urban Turk and Belgian adolescents. According to Barber et al. (2005), who also found that psychological control was the best predictor of adolescents' depressive symptoms across 11 cultural groups, psychological control inhibits self-expression, autonomous action, and the development of a sense of self-efficacy, all of which are regarded as essentials for healthy emotional development in adolescence.

In light of this literature, we expected attachment avoidance to be associated primarily with the level of warmth, and attachment anxiety with psychological control. The cross-cultural consistencies led us to expect that the proposed links between attachment and parenting dimensions would apply to Turks and Belgians similarly. Furthermore, in Barber et al. (2005) perceived mothering and fathering dimensions had parallel patterns of associations with adolescent outcomes crossculturally; hence, we predicted that these specific associations would be found for both mothers and fathers in the two cultural contexts.

\section{Culture, parenting, and attachment}

Beyond the proposed culture-general relation between psychological control and attachment anxiety, we also hypothesized a culture-specific link between psychological control and attachment avoidance. In Western contexts, for example in Canada and Belgium, high parental control is viewed as a deviant practice and implies lack of parental warmth (e.g., Rudy \& Grusec, 2001; Soenens, Vansteenkiste, Duriez, \& Goossens, 2006). It also reflects a negative parental disposition, such as authoritarian personality (Kağıtçıbaşı, 1970). Soenens, Elliot, et al. (2005) and Soenens, Vansteenkiste, et al. (2006) identified maladaptive perfection and discomfort with their role as a secure base as sources of psychological control in parents of Belgian adolescents. In such a context, psychological control, as an autonomy-inhibiting and manipulative parenting strategy, may not only undermine the adolescent's ability of self-expression without fear of rejection or abandonment but may also interfere with the development of trust and reliance on others which are key to intimate and secure attachment. In line with this argument, a study of Belgian adolescents and their parents showed that paternal and maternal psychological control, as indexed by parents' and adolescents' reports, was associated with loneliness and relational aggression in adolescents (Soenens, Vansteenkiste, Goossens, Duriez, \& Niemic, 2008).

By contrast, in the majority of non-Western cultures, for example, in Chinese, Egyptian, Korean, and Turkish societies where interdependence and subordination to group goals are prioritized over independence and self-goals, psychological control is used normatively to instill interdependence and obedience in the child (Kağıtçıbaşı, 1970; Rudy \& Grusec, 2001) and generally occurs within a context of warm parenting (Güngör, 2008; Kağıtçıbaş1, 1970). According to Chao (1994), psychological control in China is related to child-centered training rather than adult-centered punishment and is aimed at socializing the child into relational harmony and embeddedness with others. Likewise, parental, especially paternal, control and authority are goal-oriented in Turkish families and applied with particular emphasis on the child's acquisition of socially appropriate manners and interdependence (Kağıtçıbaş1, 2007). In other words, in exerting restriction and control, Turkish parents emphasize social harmony and expectations towards interpersonal closeness, rather than distance which characterizes attachment avoidance. On these bases, therefore, we expected psychological control to be primarily associated with attachment anxiety across cultures and, after controlling for this relation, also to correlate with attachment avoidance in a culture-specific way: Psychological control would be associated with attachment avoidance in Belgian adolescents, but the relation would be attenuated in Turk adolescents. Moreover, because psychological control of fathers is more normative in Turkish culture, we expected the cultural difference to be larger for fathers than for mothers between the two cultures. Given that research is unclear to allow us to relate psychological control to attachment anxiety in a culture-specific way, we tested the moderating role of culture in the link between psychological control and anxiety as an exploratory part of this study.

\section{Method}

\section{Participants and procedure}

A total of 533 adolescents in different schools in prosperous and poorer neighborhoods in Ankara, Turkey, and in the Dutch-speaking part of Belgium, Flanders, participated. After exclusion of 8 cases who returned questionnaires fully or largely incomplete, data from 262 Turk and 263 Belgian adolescents were analyzed, with 98\% and 97\% response rates, respectively. Table 1 shows the demographic characteristics of the samples. Turk and Belgian samples were similar in terms of age and the distribution of gender. The larger SD for Belgians' age, however, has mainly to do with the different organizations of high schools in the two countries. In Turkey, high schools typically consist of 3 grades; in Belgium, secondary education consists of three consecutive parts, each of which lasts 2 years. During the last 4 years students follow specialized tracks (e.g., general, technical or vocational education) as is the case for Turkish students during 3 years of high school. The data of the present study were collected from all three grades of high school in Turkey, and last 4 years of secondary education in Belgium. The percentages of students from first to last grade were 40, 31, and 29 in Turkey; and 30, 26, 23, and 21 in Belgium, respectively. 
Table 1

Demographic characteristics and descriptive measures of Turk and Belgian adolescents.

\begin{tabular}{|c|c|c|c|c|c|}
\hline & \multicolumn{2}{|l|}{ Turk } & \multicolumn{2}{|c|}{ Belgian } & \multirow[t]{2}{*}{$F / \chi^{2}(\mathrm{~d} f)$} \\
\hline & $\mathrm{M}$ & SD & M & SD & \\
\hline Age (years) & 15.85 & .90 & 15.69 & 1.43 & $2.44(1 / 523)$ \\
\hline Gender $(\% \text { female })^{\mathrm{a}}$ & 57 & & 64 & & $2.41(1)$ \\
\hline Mother education & 3.14 & 1.32 & 3.64 & .76 & $28.22^{* *}(1,521)$ \\
\hline Father education & 3.65 & 1.19 & 3.68 & .88 & $.16(1522)$ \\
\hline Maternal warmth & 3.13 & .64 & 3.04 & .56 & $2.97(1 / 522)$ \\
\hline Maternal control & 2.49 & .54 & 2.26 & .46 & $26.12^{* *}(1 / 522)$ \\
\hline Paternal warmth & 2.86 & .67 & 2.80 & .56 & $1.11(1 / 516)$ \\
\hline Paternal control & 2.44 & .52 & 2.18 & .45 & $37.92^{* *}(1 / 520)$ \\
\hline Attachment avoidance & 2.24 & .43 & 1.91 & .39 & $84.52^{* *}(1 / 521)$ \\
\hline Attachment anxiety & 2.39 & .53 & 2.19 & .40 & $24.74^{* *}(1 / 523)$ \\
\hline
\end{tabular}

${ }^{* *} p<.01$.

a Test of group difference is a Chi-square.

The median age was 16 years for both samples. Parental education was assessed on a scale on which $1=$ no formal education, 2 = primary school education, $3=$ elementary school education, $4=$ high school education, and $5=$ higher education. Father education did not differ between the two groups, but Turk mothers were less educated than Belgian mothers, possibly reflecting both greater importance on male education and status in traditional Turkish families and differences in the years of mandatory education in two countries. Mandatory education in Turkey was a primary school education until recently, and it is high school in Belgium.

Data were collected with the permission of the Ministry of Education in Turkey and of school principals in Belgium. All adolescents were informed of the general purpose and intended use of the research. They were aware of confidentiality and anonymity and their right to participate or to decline to participate entirely or in any part of the research. The questionnaires were administered during class sessions by the first author and/or a teacher. Completion of all questionnaires took approximately $1 \mathrm{~h}$.

\section{Measures}

Data collection instruments included demographic questions, parenting style, and attachment style scales. Measures originally developed in Turkish were adapted to Dutch for Belgians, and measures originally developed in English were adapted to Turkish and Dutch by bilingual natives (van de Vijver \& Leung, 1997). Standard back-translation procedures were followed. Disagreements in translations were resolved through discussions about the meaning of the source items.

\section{Parental warmth and control}

The 22-item Perceived Parenting Styles Scale (Sümer \& Güngör, 1999b) was used to investigate perceived parental warmth (e.g., "She/He supports me in dealing with my problems." and "She/He always talk to me in a comforting way.") and perceived parental psychological control (e.g., "She/He wants to control everything I do.", “She/He doesn't forgive me if I disobey her/his rules."). Participants are asked to indicate the level of agreement with each item once for mother and once for father on a scale from 1 (not true at all) to 4 (entirely true). The scale has seen use with high school students in Turkey and Belgium with satisfactory internal reliabilities ranging between .72 for paternal control and .92 for maternal warmth across groups (Güngör, 2008).

Cross-cultural construct equivalence of the two dimensions of the scale was tested using Simultaneous Components Analysis (SCA) for perceived mothering and fathering (Kiers, 1990). The two-factor solution with varimax rotation explained $43.85 \%$ of variance for perceived maternal and $43.65 \%$ of variance for perceived paternal style, and were almost equal to the variances explained by separate PCAs (43.89\% and $43.72 \%$, respectively). The items in the first component were associated with "warmth" and those in the second component with "psychological control" in both maternal and paternal style scales. The contents of the components were identical to the original scale, with the exception of one item ("She/He does not criticize me when I do something in conflict with her/his opinion.") which loaded on parental control instead of warmth. Internal reliabilities for the two subscales were high, .91 and .80 for maternal warmth and control and .91 and .79 for paternal warmth and control among Turks and .90, 77, .89, and .78 for Belgians, respectively.

\section{Attachment avoidance and anxiety}

The 36-item Experiences in Close Relationships Inventory (ECR; Brennan et al., 1998) measures attachment avoidance and attachment anxiety with romantic partners. Studies on various samples and in various languages, including Dutch, have demonstrated the reliability and construct validity of this scale (Brennan et al., 1998; Conradi, Gerlsma, van Duijn, \& de Jonge, 2006). Güngör (2000) administered the scale to 657 high school students in Turkey by wording the items to refer to closest friends, including romantic partners, and reported high internal reliabilities, .81 for avoidance and .84 for anxiety. In addition, 
avoidance was distinctively related to distrust to others, whereas anxiety was associated with depression and anxiety, providing evidence for the external validity.

In the present study, adolescents were instructed to think of their relationships with their closest friends and romantic partners and indicate how they generally experience these relationships in terms of the items of avoidance (e.g., "I try to avoid getting too close to my friends.") and anxiety ("I worry about being abandoned.") on a scale ranging from 1 (strongly disagree) to 4 (strongly agree). A two-factor solution yielded by SCA represented parallel dimensions for avoidance and anxiety. The common factor solution explained $30.53 \%$ of the variance, which was almost equal to the variance accounted for by PCA (30.71\%). SCA generated the same variable loadings on the components as in the original scale, with two exceptions: An item that was originally designed to measure avoidance ("I find it difficult to allow myself to depend on my friends.") had very low weights on both dimensions, and an item for anxiety crossloaded on both components ("I often want to merge completely with my friends, and this sometimes scares them away."). These items were omitted, and further analyses were conducted on the remaining 17 items on each dimension. The alphas were high, .76 and .85 for avoidance and anxiety among Turks, and .88 and .83 , among Belgians, respectively.

\section{Results}

First, we report descriptive statistics and relevant correlations for all variables. Next, we report final results of hierarchical regression models that were designed to identify unique associations of perceived parental warmth and perceived parental psychological control with attachment avoidance and anxiety.

\section{Descriptive information and correlations}

As shown in Table 1, both Turk and Belgian adolescents rated their parents as relatively warm and noncontrolling. Moreover, parents were perceived as similarly warm by adolescents in the two cultural groups. Both Turk mothers and fathers received higher ratings on control than did Belgian mothers and fathers. Turk adolescents also reported higher avoidance and anxiety than Belgians, but adolescents in both groups had relatively low avoidance and anxiety, as expressed by the average scores below the scale mid-point (2.50).

As shown in Table 2, maternal and paternal warmth were significantly and negatively correlated with attachment avoidance and anxiety for both Turks and Belgians, whereas maternal and paternal psychological control showed significant and positive relations with the attachment dimensions. Increased warmth and decreased control were associated with lower attachment avoidance and anxiety. However, high psychological control from father was related to high avoidance in Belgians, and avoidance was independent of the ratings of parental control in Turks.

\section{Predicting peer attachment}

We were interested in finding, first, the linear combination of parenting style dimensions that correlates maximally with different attachment outcomes and, second, the moderating role of culture between psychological control and two attachment dimensions. Accordingly, a hierarchical series of three regression models for each attachment dimension was fit. Prior to these regression analyses, the two cultural groups were dummy-coded and continuous variables (perceived warmth and control from mother and father) were centered. To investigate the interaction of culture and psychological control in predicting the attachment dimensions, two interaction terms were created (Centered maternal/paternal control by Dummycoded cultural groups). The first model fit a block of demographics (adolescents' age and gender and mothers' education) which were significantly correlated with other predictors and the dependent variables (see Table 3). Father education showed significant correlations with parenting dimensions among Turks, but we did not use father education as a covariate for two reasons: First, correlations of maternal education with other variables were relatively higher in magnitude than those for paternal education, and, second, the two cultural groups differed in the level of maternal but not in paternal education. The second model added a block consisting of parenting dimensions and cultural group. The third model included maternal or

Table 2

Correlations between perceived parenting and attachment dimensions in Turk and Belgian adolescents.

\begin{tabular}{|c|c|c|c|c|c|c|c|c|c|c|}
\hline & \multicolumn{5}{|l|}{ Turks } & \multicolumn{5}{|c|}{ Belgians } \\
\hline & 1 & 2 & 3 & 4 & 5 & 1 & 2 & 3 & 4 & 5 \\
\hline \multicolumn{11}{|l|}{ Perceptions of Parenting } \\
\hline 1. Maternal warmth & - & & & & & - & & & & \\
\hline 2. Maternal control & $-.42^{* *}$ & - & & & & $-.36^{* *}$ & - & & & \\
\hline 3. Paternal warmth & $.56^{* *}$ & $-.24^{* *}$ & - & & & $.53^{* *}$ & -.12 & - & & \\
\hline 4. Paternal control & $-.28^{* *}$ & $.77^{* *}$ & $-.25^{* *}$ & - & & $-.13^{*}$ & $.58^{* *}$ & $-.15^{*}$ & - & \\
\hline 5. Avoidance & $-.30^{* *}$ & $.14^{*}$ & $-.16^{*}$ & .06 & - & $-.24^{* *}$ & $.16^{*}$ & $-.15^{*}$ & $.17^{* *}$ & - \\
\hline 6. Anxiety & $-.19^{* *}$ & $.27^{* *}$ & $-.23^{* *}$ & $.29^{* *}$ & .01 & $-.22^{* *}$ & $.33^{* *}$ & $-.21^{* *}$ & $.29^{* *}$ & $.16^{*}$ \\
\hline
\end{tabular}

${ }^{*} p<.05 .{ }^{* *} p<.01$. 
Table 3

Correlations of demographic variables with perceived parenting and attachment dimensions in Turk and Belgian adolescents.

\begin{tabular}{|c|c|c|c|c|c|c|c|c|}
\hline & \multicolumn{4}{|l|}{ Turks } & \multicolumn{4}{|l|}{ Belgians } \\
\hline & Gender & Age & $\begin{array}{l}\text { Mother } \\
\text { education }\end{array}$ & $\begin{array}{l}\text { Father } \\
\text { education }\end{array}$ & Gender & Age & $\begin{array}{l}\text { Mother } \\
\text { education }\end{array}$ & $\begin{array}{l}\text { Father } \\
\text { education }\end{array}$ \\
\hline Maternal control & -.01 & $-.25^{* *}$ & $-.18^{* *}$ & $-.15^{*}$ & .10 & $-.16^{* *}$ & $.15^{*}$ & .08 \\
\hline Paternal warmth & .11 & -.12 & $.20^{* *}$ & $.19^{* *}$ & -.02 & $-.21^{* *}$ & .00 & .04 \\
\hline Paternal control & .03 & $-.20^{* *}$ & $-.17^{* *}$ & -.10 & -.02 & $-.21^{* *}$ & .12 & .06 \\
\hline Attachment avoidance & -.07 & $-.14^{*}$ & $-.25^{* *}$ & -.11 & $.17^{* *}$ & .00 & .02 & .04 \\
\hline Attachment anxiety & $-.14^{*}$ & .01 & .02 & -.05 & -.05 & $.21^{* *}$ & .00 & -.02 \\
\hline
\end{tabular}

Note: Gender: 0 = girls, 1 = boys. ${ }^{*} p<.05 .{ }^{* *} p<.01$.

paternal control by culture interaction. The models did not show problematic levels of multicollinearity; tolerance values were greater than .20 , ranging from .22 to .98 , and VIF statistics were less than 4, ranging from 1.05 to 3.38 .

\section{Factors associated with attachment avoidance}

Regression analysis with all the variables in the equation was significant, $R=.47, F(9,506)=16.13, p<.01$. As shown in Table 4 , all three steps resulted in a significant change in $R^{2}$. In Step 3, there was a significant association for maternal education. Adolescents with more educated mothers were less avoidant. As expected, high maternal warmth was significantly associated with low avoidance: As ratings of maternal warmth increased, avoidance decreased. Significant differences also emerged between Turks and Belgians: Turks rated themselves as more avoidant than did Belgians. In testing the moderating role of culture in the association between attachment avoidance and psychological control, the Culture by Paternal control interaction was significant. A plot with regression lines representing Turks and Belgians illustrates this effect (Fig. 1). As hypothesized, for Belgians, increased attachment avoidance was associated with higher perceived control from fathers, simple slope $=.10, t(506)=2.00, p<.05$. By contrast, attachment avoidance was not associated with paternal control for Turks, simple slope $=-.05, t(506)=-.83, n s$. Addition of the interaction term including Maternal control by Culture did not add to the model significantly, hence was not shown.

\section{Factors associated with attachment anxiety}

Regression analyses with all the independent variables in the equation resulted in a significant $R$, but interaction terms in the third step did not add significantly to the model; hence, the analyses were repeated without interactions. $R$ yielded by the new model was $.44, F(8,516)=15.61, p<.01$. The $R^{2}$ difference was significant at the end of each step. As shown in Table 5 , age and gender were significantly correlated with anxiety in Step 2; anxiety increased with age, and girls scored higher on attachment anxiety than did boys. As predicted, higher maternal and paternal psychological control were significantly associated with higher attachment anxiety. Father warmth also emerged as a significant correlate of attachment anxiety: As ratings of paternal warmth increased, attachment anxiety decreased. Finally, the two cultural groups differed in terms of the level of anxiety: Turks were more anxious in their attachment to their peers than were Belgians.

Table 4

Summary of hierarchical regression analyses for attachment avoidance.

\begin{tabular}{|c|c|c|c|c|c|c|c|c|c|}
\hline \multirow[t]{3}{*}{ Variables } & \multicolumn{9}{|c|}{ Hierarchical regression models } \\
\hline & \multicolumn{3}{|c|}{ Model 1} & \multicolumn{3}{|c|}{ Model 2} & \multicolumn{3}{|c|}{ Model 3} \\
\hline & $b$ & SEB & $\beta$ & $b$ & SEB & $\beta$ & $b$ & SEB & $\beta$ \\
\hline \multicolumn{10}{|l|}{ Adolescent demographics } \\
\hline Age & -.01 & .02 & -.03 & -.03 & .02 & -.08 & -.03 & .02 & -.07 \\
\hline Gender & .02 & .04 & .03 & .01 & .04 & .01 & .01 & .04 & .01 \\
\hline Mother education & -.09 & .02 & $-.22^{* *}$ & -.04 & .02 & $-.09^{*}$ & -.04 & .02 & $-.10^{*}$ \\
\hline \multicolumn{10}{|l|}{ Perceptions of parenting } \\
\hline Maternal warmth & & & & -.17 & .04 & $-.22^{* *}$ & -.16 & .04 & $-.22^{* *}$ \\
\hline Maternal control & & & & .00 & .05 & .01 & .02 & .05 & .02 \\
\hline Paternal warmth & & & & -.01 & .04 & -.01 & -.01 & .04 & -.01 \\
\hline Paternal control & & & & -.03 & .05 & .03 & -.05 & .06 & -.06 \\
\hline Culture & & & & -.33 & .04 & $-.38^{* *}$ & -.32 & .04 & $-.36^{* *}$ \\
\hline Paternal control by culture & & & & & & & .15 & .7 & $.11^{*}$ \\
\hline$R^{2}$ & & .05 & & & .20 & & & .22 & \\
\hline$R^{2} \Delta$ for model & & .05 & & & .17 & & & .01 & \\
\hline$F$ for $R^{2} \Delta$ & & $8.99^{* *}$ & & & $21.51^{* *}$ & & & $4.32^{*}$ & \\
\hline
\end{tabular}

Note: Gender: $0=$ girls, $1=$ boys. Culture: $0=$ Turks, $1=$ Belgians.

${ }^{*} p<.05 .{ }^{* *} p<.01$. 


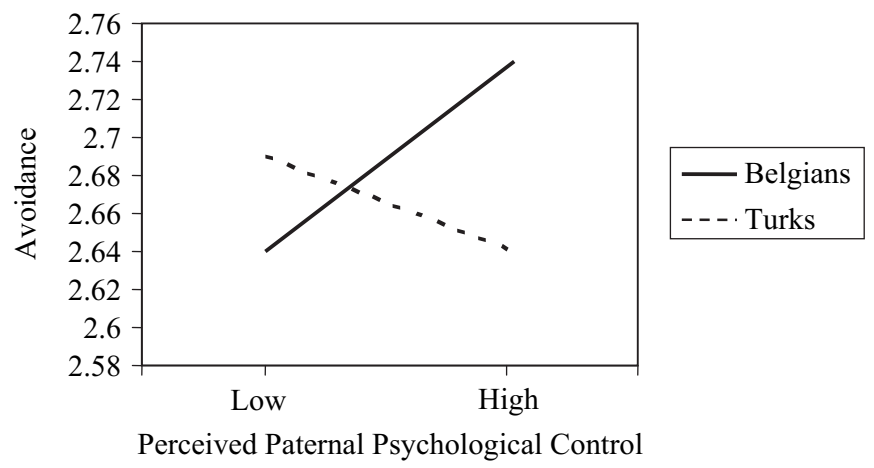

Fig. 1. Attachment avoidance as a function of culture and paternal psychological control.

\section{Discussion}

This cross-cultural study explored specific associations between the central constructs of two distinct sub-disciplines attachment and perceived parenting styles - that have not been fruitfully studied together previously in the domain of peer attachment. Although Turks and Belgians come from contrasting cultural contexts, maternal warmth and maternal psychological control showed culturally unconditioned relations with attachment avoidance and anxiety, respectively. Paternal warmth was not related to attachment avoidance, but low warmth and high psychological control from fathers predicted high attachment anxiety. In addition, culture moderated the link between fathers' psychological control and attachment avoidance; fathers' control predicted avoidance for Belgians but not for Turks. Overall, the findings supported our hypotheses regarding the links between perceived maternal dimensions and peer attachment but partially supported those concerning paternal dimensions and attachment dimensions.

Cross-culturally, mothers were judged to play key roles in attachment avoidance through their education level and warmth. We did not expect warmth to link to anxiety but we did expect an association between control and anxiety; father warmth, as well as control, was significantly associated with anxiety. Note that we drew our expectations mainly from studies of mother-child relationships. Limited data on perceived fathering points to a unique role fathers play in adolescents' emotion regulation, depressive symptoms, and anxiety in Western cultures (e.g., McFarlane, Bellissimo, \& Norman, 1995; Rohner, 1986). Barber et al. (2005) reported that maternal warmth is a significant predictor of adolescent depression, but the impact of paternal warmth is likely to be more dominant in the long-run. Notably, much of evidence in support of our findings comes from studies of divorced families that focused on perceived fathering and mothering simultaneously. In one instance, father involvement and closeness, as perceived by adolescents, predicted less adolescent anxiety and withdrawal, and the effect was significant beyond maternal closeness (Thomas \& Forehand, 1993). Likewise, Summers, Forehand, Armistead, and Tannenbaum (1998) showed longitudinally in divorced families that adolescents' perceived paternal closeness, more than perceived maternal closeness, predicted lower anxiety and fewer depressive symptoms in young adulthood. Because our data do not include information on adolescents' family structure, whether the findings relating

Table 5

Summary of hierarchical regression analyses for attachment anxiety.

\begin{tabular}{|c|c|c|c|c|c|c|}
\hline \multirow[t]{3}{*}{ Variables } & \multicolumn{6}{|c|}{ Hierarchical regression models } \\
\hline & \multicolumn{3}{|c|}{ Model 1} & \multicolumn{3}{|c|}{ Model 2} \\
\hline & $b$ & SEB & $\beta$ & $b$ & SEB & $\beta$ \\
\hline \multicolumn{7}{|c|}{ Adolescent demographics } \\
\hline Age & .05 & .02 & $.11^{*}$ & .06 & .02 & $.14^{* *}$ \\
\hline Gender & -.08 & .05 & -.08 & -.09 & .04 & $-.08^{*}$ \\
\hline Mother education & -.02 & .02 & -.05 & .02 & .02 & .05 \\
\hline \multicolumn{7}{|c|}{ Perceptions of Parenting } \\
\hline Maternal warmth & & & & -.02 & .05 & -.032 \\
\hline Maternal control & & & & .20 & .06 & $.20^{* *}$ \\
\hline Paternal warmth & & & & -.09 & .04 & $-.11^{*}$ \\
\hline Paternal control & & & & .18 & .06 & $.18^{* *}$ \\
\hline Culture & & & & -.14 & .05 & $-.14^{* *}$ \\
\hline$R^{2}$ & & .02 & & & .22 & \\
\hline$R^{2} \Delta$ for model & & .02 & & & .20 & \\
\hline
\end{tabular}

Note: Gender: $0=$ girls, $1=$ boys. Culture: $0=$ Turks, $1=$ Belgians.

${ }^{*} p<.05 .{ }^{* *} p<.01$. 
perceived fathering to attachment avoidance hold similarly for intact or divorced families remains to be addressed explicitly by future research. Nevertheless, the present study suggests that paternal warmth and psychological control are more strongly associated with attachment anxiety rather than with attachment avoidance in adolescents from both Western and non-Western cultures.

Regarding why low warmth from fathers was related to high attachment anxiety, two explanations suggest themselves. The first is related to the differential nature of adolescents' relationships with mothers and with fathers. Mothers act as primary caregivers, but fathers are more likely to support autonomy development in their children. Fathers, as compared to mothers, tend to encourage competitiveness, independence, and risk taking (Cabrera, Tamis-LeMonda, Bradley, Hofferth, \& Lamb, 2000). At the same time, adolescents who feel their fathers as "available" when needed have fewer conflicts with their friends (Lieberman, Doyle, \& Markiewicz, 1999). In adolescence, during which the child's relationships extends beyond the family and autonomy achievement is considered to be a main developmental task (Steinberg \& Silk, 2002), warmth from fathers may act as a source of confidence and comfort, leading to more positive self-perceptions and less dependence on the confirmation of others.

A second explanation may be that fathers impact the level of attachment anxiety in their children more indirectly. Warm fathering tends to create a family environment that contributes to marital satisfaction of parents (Lamb, 1986), who in turn more efficiently cooperate in child care. In this family systems view (Bornstein \& Sawyer, 2005), the children of highly involved fathers thus benefit from the improved positive climate of the family context and experience emotional comfort in the family. How and why paternal warmth has a role chiefly on attachment anxiety, and how adolescents derive a sense of self-worth from a loving relationship with their fathers, need to be addressed explicitly in future studies.

Adolescent gender and age were related to attachment anxiety. That female adolescents reported higher attachment anxiety than male adolescents is consistent with the gendered socialization of relatedness and with past studies showing that girls tend to be more concerned with close relationships (Ruble, Martin, \& Berenbaum, 2006). Increased attachment anxiety with age might have to do with the fact that our sample consisted of high school students. As adolescents get older, the uncertainty of the future of their present close relationships may increase in salience, leading to heightened fear of rejection by the world beyond school and existing peer groups. Whether this prediction is correct, and whether greater attachment anxiety in later adolescence has negative consequences in adaptation to life after school, also need to be examined in future studies.

Beyond these culture-general patterns of relations between parenting and attachment style dimensions, a culture-specific association emerged, confirming our hypothesis. Judging fathers as high on psychological control was related to higher avoidance among Belgians but not among Turks, although Turks rated their fathers as more controlling than did Belgians. At the same time, Turk and Belgian adolescents were similar in the degree of warmth they perceived from their parents. These findings suggest that parental control, together with warmth, which characterizes traditional Turkish parenting style (Kağıtçıbaş1, 1970), is still prevalent in urban Turkish families. However, attachment anxiety and avoidance were also high among Turks. It may be that, urban Turkish youth attribute their parents' restrictive control to norms in their culture, and, thus, may not perceive parental control negatively, but this does not necessarily make them immune to the negative impact of psychological control. In fact, after controlling for adolescents' age and gender and maternal education, and with other parenting dimensions being held constant, high parental control were associated with high attachment anxiety in both cultural groups.

That Turk adolescents scored high on attachment avoidance as compared with Belgians was unexpected because most cross-cultural studies of attachment styles suggest that avoidance is more prevalent in individualist cultures than in collectivist ones. However, the majority of these findings were obtained either in infant (Van IJzendoorn \& Kroonenberg, 1988) or adult studies (Schmitt et al., 2004). Presumably, rapidly changing socioeconomic contexts and newly emerging life styles force old and new values to live side by side and engender trust issues, making attachment avoidance more likely in Turk adolescents. Ammaniti, van IJzendoorn, Speranza, and Tambelli (2000) observed in a longitudinal study that a dismissing style characterized by high avoidance increased in intensity among Italian adolescents from 10 to 14 years, and they reasoned that avoidance might be functional for individuation from parents to achieve a distinct personal identity. Thus, in a cultural context where interdependence is emphasized and the boundaries between self and others are highly permeable, as argued to be the case in Turkish society (Kağıtçıbaşı, 2007), adolescents may need to stress interpersonal distance more strongly to achieve autonomy. More studies are needed to arrive at safer conclusions about the prevalence and function of enhanced avoidance in adolescents who live in modernizing non-Western cultures.

Our data are cross-sectional and come from self-reports of adolescents. Although we were specifically interested in how adolescents associate their mental representations of the dimensions of parenting and peer attachment, common source variance in the measures can still be a problem. Relatedly, it is possible that adolescents who experience negative relations with their peers may show negative response bias in assessing their parents or vice versa. We cannot specify causal flow and can only speculate on who is influencing whom. The present study shows that parenting and attachment style perspectives can be integrated into a parsimonious framework to explore the parenting processes involved in peer attachment. Within this framework, perceiving high warmth and low psychological control seemed to be critical to "sensitive" parenting by showing distinct relations to the specific aspects of secure attachment in adolescence. In addition, the finding of a culture-specific link from psychological control to attachment avoidance underscores the necessity of taking into account cultural context of development in determining developmental pathways of secure and insecure attachment in adolescence. 


\section{References}

Allen, J. P., \& Land, D. (1999). Attachment in adolescence. In J. Cassidy, \& P. R. Shaver (Eds.), Handbook of attachment: Theory, research, and clinical applications (pp. 319-335). New York: Guilford Press.

Allen, J. P., Moore, C. M., Kuperminc, G. P., \& Bell, K. L. (1998). Attachment and adolescent psychosocial functioning. Child Development, 69. $2406-1419$.

Ammaniti, M., van IJzendoorn, M. H., Speranza, A. M., \& Tambelli, R. (2000). Internal working models of attachment during late childhood and early adolescence: an exploration of stability and change. Attachment and Human Development, 2(3), 328-346.

Barber, B. K. (1996). Parental psychological control: evisiting a neglected construct. Child Development, 67(6), 3296-3319.

Barber, B. K., Stolz, H. E., \& Olsen, J. A. (2005). Parental support, psychological control, and behavioral control: assessing relevance across time, culture, and method. Monographs of the Society for Research in Child Development, 70(4).

Bartholomew, K., \& Horowitz, L. (1991). Attachment styles among young adults: a test of a four category model. Journal of Personality and Social Psychology, $61,226-241$.

Bornstein, M. H., \& Lansford, J. E. (2009). Parenting. In M. H. Bornstein (Ed.), The handbook of cultural developmental science. Part 1. Domains of development across cultures (pp. 259-277). New York, NY: Taylor \& Francis (Group).

Bornstein, M. H., \& Sawyer, J. (2005). Family systems. In K. McCartney, \& D. Philips (Eds.), Blackwell handbook of early childhood development (pp. 381-398). Malden, MA: Blackwell.

Brennan, K. A., Clark, C. L., \& Shaver, P. R. (1998). Self-report measurement of adult attachment: an integrative overview. In J. A. Simpson, \& W. S. Rholes (Eds.), Attachment theory and close relationships (pp. 46-76). New Yor: Guilford Press.

Cabrera, N. J., Tamis-LeMonda, C. S., Bradley, R. H., Hofferth, S., \& Lamb, M. E. (2000). Fatherhood in the twenty-first century. Child Development, 71, $127-136$.

Chao, R. (1994). Beyond parental control and authoritarian parenting style: understanding Chinese parenting through the cultural notion of training. Child Development, 65, 1111-1120.

Conger, K. J., Conger, R. D., \& Scaramella, L. V. (1997). Parents, siblings, psychological control, and adolescent adjustment. Journal of Adolescent Research, 12(1), 113-138.

Conradi, H. J., Gerlsma, J., van Duijn, M., \& de Jonge, P. (2006). Internal and external validity of the experiences in close relationships questionnaire in an American and two Dutch samples. European Journal of Psychiatry, 20(4), 258-269.

Day, R. D., \& Acock, A. (2004). Youth ratings of family processes and father role performance of resident and nonresident fathers. In R. D. Day, \& M. E. Lamb (Eds.), Conceptualizing and measuring father involvement (pp. 273-292). Mahwah, NJ: Lawrence Erlbaum.

Dekovic, M., \& Meeus, W. (1997). Peer relations in adolescence: effects of parenting and adolescents' self-concept. Journal of Adolescence, $20,163-176$.

Doyle, A. B., \& Markiewicz, D. (2005). Parenting, marital conflict and adjustment from early- to mid-adolescence: mediated by adolescent attachment style? Journal of Youth and Adolescence, 34, 97-110.

Fraley, R. R., \& Davis, K. E. (1997). Attachment formation and transfer in young adults' close friendships and romantic relationships. Personal Relationships, 4, $131-144$.

Fraley, R. C., \& Shaver, P. R. (2000). Adult romantic attachment: theoretical developments, emerging controversies, and unanswered questions. Review of General Psychology, 4, 132-154.

Güngör, D. (2000). Bağlanma stillerinin ve zihinsel modellerin kuşaklararası aktarımında anababalık stillerinin rolü. [The role of parenting styles in the intergenerational transmission of attachment styles and mental models]. Unpublished dissertation. Ankara, Turkey: Ankara University.

Güngör, D. (2008). The meaning of parental control in migrant, sending, and host communities: adaptation or persistence? Applied psychology: An International Review, 57(3), 397-416.

Hazan, C., \& Shaver, P. R. (1987). Romantic love conceptualized as an attachment process. Journal of Personality and Social Psychology, 52, 511-524.

Kaıtçıbaşı, Ç (1970). Social norms and authoritarianism: a Turkish-American comparison. Journal of Personality and Social Psychology, 16(39), 444-451.

Kaıtçıbaşı, Ç (2007). Family, self, and human development: Theory and application (2nd ed.). Mahwah, NJ: Lawrence Erlbaum.

Khaleque, A., \& Rohner, R. P. (2002). Perceived parental acceptance-rejection and psychological adjustment: a meta-analysis of cross-cultural and intracultural studies. Journal of Marriage and Family, 64(1), 54-64.

Kiers, H. A. L. (1990). SCA. A program for simultaneous components analysis of variables measured in two or more populations. Groningen: iec ProGAMMA.

Kobak, R. R., \& Sceery, A. (1988). Attachment in late adolescence: working models, affect regulation, and representations of self and others. Child Development, 59, 135-146.

Lamb, M. E. (Ed.). (1986). The fathers' role: Applied perspectives. New York: Wiley.

Levy, K. N., Blatt, S. J., \& Shaver, P. R. (1998). Attachment styles and parental representations. Journal of Personality and Social Psychology, 74(2), 407-419.

Lieberman, M., Doyle, A. B., \& Markiewicz, D. (1999). Developmental patterns in security of attachment to mother and father in late childhood and early adolescence: associations with peer relations. Child Development, 70(1), 202-213.

McFarlane, A. H., Bellissimo, A., \& Norman, G. R. (1995). Family structure, family functioning and adolescent well-being: the transcendent influence of parental style. Journal of Child Psychology/Psychiatry, 36, 847-864.

Mikulincer, M., \& Orbach, I. (1995). Attachment styles and repressive defensiveness: the accessibility and architecture of affective memories. Journal of Personality and Social Psychology, 68, 917-925.

Mikulincer, M., Shaver, P. R., \& Pereg, D. (2003). Attachment theory and affect regulation: the dynamics, development, and cognitive consequences of attachment-related strategies. Motivation and Emotion, 27(2), 77-102.

Rohner, R. P. (1986). The warmth dimension: Foundations of parental acceptance-rejection theory. Beverly Hills, CA: Sage.

Rohner, R. P., \& Veneziano, R. A. (2001). The importance of father love: history and contemporary evidence. Reivew of General Psychology, 5(4), $382-405$.

Ruble, D. N., Martin, C. L., \& Berenbaum, S. A. (2006). Gender development. In D. Kuhn, R. S. Siegler, W. Damon, \& W. Damon (Eds.), Handbook of child psychology (6th ed.).Cognition, perception, and language, Vol. 2 (pp. 858-932) Hoboken, NJ: Wiley.

Rudy, D., \& Grusec, J. E. (2001). Correlates of authoritarian parenting in individualist and collectivist cultures and implications for understanding the transmission of values. Journal of Cross-Cultural Psychology, 32(2), 202-212.

Schmitt, D. P., Alcalay, L., Allensworth, M., Allik, J., Ault, L., Austers, I., et al. (2004). Patterns and universals of adult romantic attachment across 62 cultural regions. Journal of Cross-Cultural Psychology, 35(4), 367-402.

Soenens, B., Elliot, A. J., Goossens, L., Vansteenkiste, M., Luyten, P., \& Duriez, B. (2005). The intergenerational transmission of perfectionism: parents' psychological control as intervening variable. Journal of Family Psychology, 19, 358-366.

Soenens, B., Luyckx, K., Vansteenkiste, M., Duriez, B., \& Goossens, L. (2008). Clarifying the link between parental psychological control and adolescents' depressive feelings: a test of reciprocal versus unidirectional models of influence. Merrill Palmer Quarterly, 54, 411-444.

Soenens, B., Vansteenkiste, M., Duriez, B., \& Goossens, L. (2006). In search of the sources of psychologically controlling parenting: the role of parental separation anxiety and parental maladaptive perfectionism. Journal of Research on Adolescence, 16, 539-559.

Soenens, B., Vansteenkiste, M., Goossens, L., Duriez, B., \& Niemic, C. (2008). The intervening role of relational aggression between psychological control and friendship quality. Social Development, 17, 661-681.

Soenens, B., Vansteenkiste, M., Luyten, P., Duriez, B., \& Goossens, L. (2005). Maladaptive perfectionistic self-representations: the mediational link between psychological control and adjustment. Personality and Individual Differences, 38, 487-498.

Sorkhabi, N. (2005). Applicability of Baumrind's parent typology to collective cultures: analysis of cultural explanations of parent socialization effects. International Journal of Behavioral Development, 29(6), 552-563.

Steinberg, L., \& Silk, J. S. (2002). Parenting adolescents. In M. H. Bornstein (Ed.), Handbook of parenting (2nd ed.). Children and parenting, Vol. 1 (pp. 103-133) Mahwah, NJ: Erlbaum. 
Sümer, N., \& Güngör, D. (1999a). Psychometric evaluation of adult attachment measures on Turkish samples and a cross-cultural comparison. Turkish Journal of Psychology, 14(43), 71-109.

Sümer, N., \& Güngör, D. (1999b). The impact of perceived parenting styles on attachment styles, self-evaluations and close relationships. Turkish Journal of Psychology, 14(44), 35-62.

Summers, P., Forehand, L., Armistead, L., \& Tannenbaum, L. (1998). Parental divorce during early adolescence in Caucasian families: the role of family process variables in predicting the long-term consequences for early adult psychosocial adjustment. Journal of Consulting and Clinical Psychology, 66, 327-336.

Thomas, M., \& Forehand, R. (1993). The role of paternal variables in divorced and married families: predictibility of adolescent adjustment. American Journal of Orthopsychiatry, 63, 126-135.

Van IJzendoorn, M. H., \& Kroonenberg, P. M. (1988). Cros-cultural patterns of attachment: a meta-analysis of the strange situation. Child Development, 59(1), 147-156.

van de Vijver, F. J. R., \& Leung, K. (1997). Methods and data analysis for cross-cultural research. Thousand Oaks, CA: Sage.

Yang, C., Hart, C. H., Nelson, D. A., Porter, C. L., Olsen, S. F., Robinson, C. C., et al. (2003). Fathering in a Beijing, Chinese sample: associations with boys' and girls' negative emotionality and aggression. In R. D. Day, \& M. E. Lamb (Eds.), Conceptualizing and measuring father involvement (pp. 185-215). New York: Routledge. 